\title{
Caffeic Acid
}

National Cancer Institute

\section{Source}

National Cancer Institute. Caffeic Acid. NCI Thesaurus. Code C68540.

An orally bioavailable, hydroxycinnamic acid derivative and polyphenol, with potential antioxidant, anti-inflammatory, and antineoplastic activities. Upon administration, caffeic acid acts as an antioxidant and prevents oxidative stress, thereby preventing DNA damage induced by free radicals. Caffeic acid targets and inhibits the histone demethylase (HDM) oncoprotein gene amplified in squamous cell carcinoma 1 (GASC1; JMJD2C; KDM4C) and inhibits cancer cell proliferation. GASC1, a member of the KDM4 subgroup of Jumonji (Imj) domain-containing proteins, demethylates trimethylated lysine 9 and lysine 36 on histone H3 (H3K9 and H3K36), and plays a key role in tumor cell development. 